\title{
Cocaine Selectively Reorganizes Excitatory Inputs to Substantia Nigra Pars Compacta Dopamine Neurons
}

\author{
@Gerard M.J. Beaudoin III,* Jorge A. Gomez, Jessica Perkins, Julie L. Bland, ๑Alyssa K. Petko, \\ and $\mathbb{C}^{\text {Carlos A. Paladini }}$ \\ University of Texas at San Antonio Neurosciences Institute, Department of Biology, University of Texas at San Antonio, San Antonio, Texas 78249
}

Substantia nigra pars compacta ( $\mathrm{SNc}$ ) dopamine neurons and their targets are involved in addiction and cue-induced relapse. However, afferents onto SNc dopamine neurons themselves appear insensitive to drugs of abuse, such as cocaine, when afferents are collectively stimulated electrically. This contrasts with ventral tegmental area (VTA) dopamine neurons, whose glutamate afferents react robustly to cocaine. We used an optogenetic strategy to isolate identified SNc inputs and determine whether cocaine sensitivity in the mouse SNc circuit is conferred at the level of three glutamate afferents: dorsal raphé nucleus (DR), pedunculopontine nucleus (PPN), and subthalamic nucleus (STN). We found that excitatory afferents to SNc dopamine neurons are sensitive to cocaine in an afferent-specific manner. A single exposure to cocaine in vivo led to PPN-innervated synapses reducing the AMPA-to-NMDA receptor-mediated current ratio. In contrast to work in the VTA, this was due to increased NMDA receptor function with no change in AMPA receptor function. STN synapses showed a decrease in calcium-permeable AMPA receptors after cocaine, but no change in the AMPA-to-NMDA ratio. Cocaine also increased the release probability at DR-innervated and STN-innervated synapses, quantified by decreases in paired-pulse ratios. However, release probability at PPN-innervated synapses remained unaffected. By examining identified inputs, our results demonstrate a functional distribution among excitatory SNc afferent nuclei in response to cocaine, and suggest a compelling architecture for differentiation and separate parsing of inputs within the nigrostriatal system.

Key words: AMPA; dorsal raphé; NMDA; optogenetics; pedunculopontine nucleus; subthalamic nucleus

\section{Significance Statement}

Prior studies have established that substantia nigra pars compacta $(\mathrm{SNc})$ dopamine neurons are a key node in the circuitry that drives addiction and relapse, yet cocaine apparently has no effect on electrically stimulated excitatory inputs. Our study is the first to demonstrate the functional impact of a drug of abuse on synaptic mechanisms of identified afferents to the SNc. Optogenetic dissection of inputs originating from dorsal raphé, pedunculopontine, and subthalamic nuclei were tested for synaptic modifications following in vivo cocaine exposure. Our results demonstrate that cocaine differentially induces modifications to SNc synapses depending on input origin. This presents implications for understanding dopamine processing of motivated behavior; most critically, it indicates that dopamine neurons selectively modulate signal reception processed by afferent nuclei.

\section{Introduction}

While ventral tegmental area (VTA) dopamine neurons have received intense scrutiny in the regulation of drug addiction, sub-

Received July 12, 2017; revised Nov. 28, 2017; accepted Dec. 9, 2017.

Author contributions: G.M.J.B. and C.A.P. designed research; G.M.J.B., J.A.G., J.P., J.L.B., A.K.P., and C.A.P. performed research; G.M.J.B. and J.A.G. analyzed data; G.M.J.B., J.A.G., and C.A.P. wrote the paper.

This research was supported by National Institutes of Health Grants MH079276 (C.A.P.), DA030530 (C.A.P.), HRD1249284 (J.A.G.), GM060655 (J.A.G.), and F31DA041303 (J.A.G.). Imaging data collection was supported by Grant G12MD007591.

The authors declare no competing financial interests.

Correspondence should be addressed to Carlos A. Paladini, University of Texas at San Antonio Neurosciences Institute, Department of Biology, University of Texas at San Antonio, One UTSA Circle, San Antonio, TX78249. E-mail: carlos.paladini@utsa.edu.

${ }^{*}$ G.M.J. Beaudoin III.'s present address: Trinity University, Department of Biology, San Antonio, TX 78212.

DOI:10.1523/JNEUROSCI.1975-17.2017

Copyright $\odot 2018$ the authors $\quad 0270-6474 / 18 / 381151-09 \$ 15.00 / 0$ stantia nigra pars compacta ( $\mathrm{SNc}$ ) dopamine neurons, which also encode critical features of drug addiction, have not been so thoroughly studied. Direct activation and inhibition of SNc dopamine neurons induce both reward and aversion, respectively (Rossi et al., 2013; Ilango et al., 2014). Prior exposure to cocaine is known to cause sensitization or increased expression of behaviors mediated by dopamine release in the dorsal striatum on subsequent exposure to cocaine (Zahniser et al., 1988; Wolf, 1998). This further suggests that SNc dopamine neurons, which project to the dorsal striatum, are affected by exposure to cocaine. Finally, SNc dopamine neuron activity is uniquely increased when a learned, cocaine-associated cue is presented in context, which may underlie cue-induced relapse (Ito et al., 2000, 2002). Given these effects, SNc dopamine neurons may be a site of cocaine action whereby synapses originating from different nuclei might respond differentially to cocaine exposure. 
One of the first effects of a single exposure to cocaine, beginning after $1 \mathrm{~d}$, is an increase in EPSCs mediated by AMPA receptors in dopamine neurons of the VTA, but apparently not the SNc (Ungless et al., 2001; Saal et al., 2003; Heikkinen et al., 2009; Lammel et al., 2011). The increase in excitatory current in the VTA is primarily due to insertion of the inward rectifying, calcium-permeable variety of AMPA receptors, without any apparent changes in presynaptic function (Ungless et al., 2001; Bellone and Lüscher, 2006). However, the experiments that produced these findings used electrical stimulation to evoke excitatory currents, masking any potential differences in the effects cocaine had on separate afferents. To dissect the influence of different identified inputs to SNc dopamine neurons, we used an optogenetic strategy to selectively stimulate three prominent SNc glutamate afferents: dorsal raphé nucleus (DR), pedunculopontine nucleus (PPN), and subthalamic nucleus (STN).

We found that optogenetic stimulation of DR, PPN, and STN afferents in vitro induces excitatory currents in SNc dopamine neurons that differ in synaptic physiology even in drug-naive animals. In animals exposed to cocaine $1 \mathrm{~d}$ before experiments, DR-innervated, PPN-innervated, and STN-innervated synapses were affected with different changes in release probability, AMPA receptor redistribution, and AMPA-to-NMDA receptor-mediated current ratios selective to each input. Thus, we demonstrate that drugs of abuse also target synaptic inputs to SNc dopaminergic neurons. Further, the dopaminergic neuron is not a passive component of the reward circuitry, but rather actively changes receptor distribution to strengthen or weaken distinct inputs.

\section{Materials and Methods}

Animal procedures. Twenty-five BALB/c mice of either sex (6-10 weeks old) were used for bilateral DR, STN, and PPN stereotaxic injections of pseudotyped AAV1-CaMKII-ChR2-EYFP virus. Fewer female mice were used, but when they were, the results were near the overall mean. Surgeries were performed while the mouse was anesthetized with $1.5 \%$ isofluorane in $1.8 \mathrm{~L} / \mathrm{min}$ oxygen. STN injections of $50-150 \mathrm{nl}$ were made using the following coordinates: anteroposterior $(\mathrm{AP}),-1.80 \mathrm{~mm}$; mediolateral (ML), $\pm 1.70 \mathrm{~mm}$; and dorsoventral (DV), $-4.31 \mathrm{~mm}$ relative to bregma. PPN injections of $100-300 \mathrm{nl}$ of the same virus were made using the following coordinates: AP, $-4.40 \mathrm{~mm}$; ML, $\pm 1.27 \mathrm{~mm}$; and DV, $-3.50 \mathrm{~mm}$. DR injections of $300 \mathrm{nl}$ of the same virus were made using the following coordinates: AP, $-4.30 \mathrm{~mm}$; ML, $\pm 0.2 \mathrm{~mm}$; and DV, -3.30 $\mathrm{mm}$. All injections were infused at $30-50 \mathrm{nl} / \mathrm{min}$. All mice were handled in accordance with state and federal regulations in procedures approved by the University of Texas at San Antonio Institutional Animal Care and Use Committee.

Electrophysiology. Unless noted otherwise, chemicals were purchased from Thermo Fisher Scientific or Sigma-Aldrich. Three to 4 weeks after surgery, mice were injected intraperitoneally with saline or $10 \mathrm{mg} / \mathrm{kg}$ cocaine in saline. Twenty-four hours after injection, brain slices were prepared and dopamine cells were identified as previously described (Goertz et al., 2015). Mice were anesthetized with isofluorane and decapitated. The brain was submerged in ice-cold cutting solution containing the following (in mM): 110 cholineCl, $2.5 \mathrm{KCl}, 1.25 \mathrm{NaH}_{2} \mathrm{PO}_{4}, 7 \mathrm{MgCl}_{2}, 0.5 \mathrm{CaCl}_{2}$, 10 dextrose, $25 \mathrm{NaHCO}_{3}, 1.3$ ascorbic acid, and 2.4 sodium pyruvate. Horizontal sections $(250 \mu \mathrm{m})$ were cut with a vibratome in ice-cold cutting solution oxygenated with $5 \% \mathrm{CO}_{2} / 95 \% \mathrm{O}_{2}$. The slices recovered for $30 \mathrm{~min}$ at $35^{\circ} \mathrm{C}$ in aCSF containing the following (in $\mathrm{mM}$ ): $126 \mathrm{NaCl}$, $2.5 \mathrm{KCl}, 1.25 \mathrm{NaH}_{2} \mathrm{PO}_{4}, 4 \mathrm{MgCl}_{2}, 2 \mathrm{CaCl}_{2}, 10$ dextrose, $25 \mathrm{NaHCO}_{3}, 1.3$ ascorbic acid, 2.4 sodium pyruvate supplemented with $0.16 \mathrm{~mm}$ l-glutathione and saturated with $5 \% \mathrm{CO}_{2} / 95 \% \mathrm{O}_{2}$. The slices were stored at room temperature for the remainder of the day. Slices were transferred to a recording chamber and perfused with $32.5-35.5^{\circ} \mathrm{C}$ aCSF supplemented with $100 \mu \mathrm{M}$ picrotoxin (Sigma-Aldrich) flowing at $1.5-3 \mathrm{ml} / \mathrm{min}$. Pipettes with 3-7 M $\Omega$ resistance were used containing the following (in mM): $135 \mathrm{CsCl}, 2 \mathrm{MgCl}_{2}, 10$ HEPES, 5 QX-314, 5 EGTA tetrasodium salt,
2 ATP-trisodium salt (MP Biomedicals), 0.2 GTP-disodium salt (MP Biomedicals), pH 7.3 and 275 mOsm osmolarity.

Recordings were made using a Multiclamp 700B amplifier (Molecular Devices). Signals were digitized at $15-30 \mathrm{kHz}$ and saved to a hard drive for analysis using the program Axograph X. Putative dopaminergic neurons within the $\mathrm{SNc}$ were identified as having a spontaneous firing rate of $<10 \mathrm{~Hz}$, action potential half-width of $>1.5 \mathrm{~ms}$, and a large hyperpolarization-activated cyclic nucleotide-gated ( $\mathrm{HCN})$ channelmediated current $\left(I_{\mathrm{h}}\right)$ in response to hyperpolarizing pulses. Cellattached mode was used to examine the spike width and spike rate of spontaneously occurring action potentials. Within $10 \mathrm{~s}$ of achieving whole-cell access, a negative voltage step $(-60$ to $-120 \mathrm{mV})$ was applied to test for the presence of $I_{\mathrm{h}}$.

A $0.05 \mathrm{~ms}$ electrical pulse was applied using a $250 \mu \mathrm{m}$ tungsten bipolar stimulator (FHC) placed rostral from a cell of interest $(\approx 200 \mu \mathrm{m})$. A $473 \mathrm{~nm}$ laser coupled to a $250 \mu \mathrm{m}$ optical fiber directed at the SNc was used for optical stimulation. Laser settings were optimized to ensure that responses were due to propagating action potentials. An example of this procedure is presented in Figure $6 C, D$. Typical settings included a laser intensity of $30 \mathrm{~mW}$ and pulse duration of $1 \mathrm{~ms}$. Electrical stimulation intensity was chosen to match the amplitude of optically evoked EPSCs (see Figs. $2 A, 4 A$ ). Once electrical and optical stimulations were matched, they were not changed for the duration of the recording. For paired pulse ratios (PPRs), the stimulus, either electrical or optical, was given in succession at a $50 \mathrm{~ms}$ interval. The holding current was monitored for 3-5 min to wait until the recording had not changed amplitude for $30 \mathrm{~s}$. Post $h o c$, the baseline was examined for changes in holding current. Access resistance was monitored and measured post hoc to ensure access resistance had not changed $>25 \%$.

AMPA-to-NMDA ratios were calculated from the ratio of the evoked AMPA and NMDA receptor-mediated EPSCs at $+40 \mathrm{mV}$. Specifically, we recorded the EPSC in control aCSF and then switched to aCSF containing 50-100 $\mu \mathrm{M}$ D-AP5 (Tocris Bioscience), to block NMDA receptors, revealing the AMPA receptor-mediated EPSC. For all buffer changes or drug wash-ins, $10 \mathrm{ml}$ of aCSF was perfused to the neuron before recording EPSCs, as this corresponded to a fourfold change in buffer at the recording cell. The AMPA receptor-mediated EPSC was subtracted from the control EPSC to calculate the NMDA receptormediated EPSC. We used $0.5 \mu \mathrm{M}$ joro spider toxin (JTx; Santa Cruz Biotechnology) and 20-100 $\mu \mathrm{M}$ 1-napthyl acetyl spermine (NASPM) trihydrochloride (Tocris Bioscience) as calcium-permeable AMPA receptor antagonists. The effect of $100 \mu \mathrm{M}$ spermine added to the internal solution was tested on five cells with no significant change in AMPA receptor rectification. The rectification index of AMPA receptor-mediated EPSCs is the ratio of the current at a holding voltage of $-60 \mathrm{mV}$ divided by the current at a holding voltage of $+40 \mathrm{mV}$. Rise time is defined as the time the EPSC rises from 20 to $80 \%$ of peak. For decay time constants, EPSCs are fit with a double exponential curve and the two $\tau$ 's and amplitudes are used to calculate the weighted average of $\tau$. Slices were fixed in $4 \%$ paraformaldehyde in PBS and stored in PBS with $0.02 \%$ sodium azide.

Statistics. A $t$ test was used for all pairwise comparisons. One-way ANOVA was used for all multiple comparisons between inputs, and two-way ANOVA was used for all comparisons between control and cocaine-injected animals. Reported $p$ values are adjusted for multiple comparisons using a Holm-Sidak correction for parametric analysis. The optically stimulated oDR-evoked, oPPN-evoked, and oSTN-evoked PPRs from control and cocaine-injected mice were normally distributed based upon the Shapiro-Wilk normality test, and so were analyzed using parametric analysis.

Imaging. Injection site images of both bright-field and YFP fluorescence were collected with a CCD camera on a fluorescent stereomicroscope. High-resolution images of afferents in SNcs were prepared from slices labeled for tyrosine hydroxylase. The slices were blocked and permeabilized in $5 \%$ normal goat serum and $0.2 \%$ Triton X-100 at room temperature for $>1 \mathrm{~h}$. Slices were incubated overnight at $4^{\circ} \mathrm{C}$ with mouse anti-tyrosine hydroxylase (1:500; Millipore) and rabbit anti-green fluorescent protein (1:1000; Life Sciences) in PBS with 1\% normal goat serum and $0.1 \%$ Triton $X-100$. The slices were washed three times for $5 \mathrm{~min}$ in PBS with $0.05 \%$ Triton X-100 and then incubated at room tempera- 
A
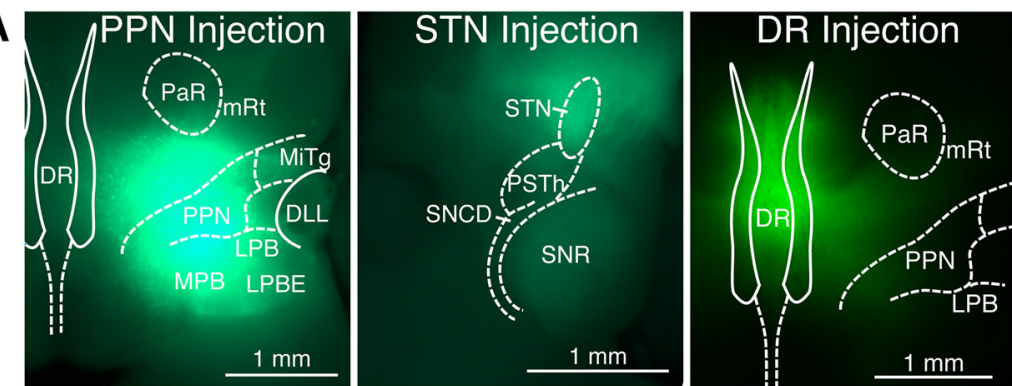

B

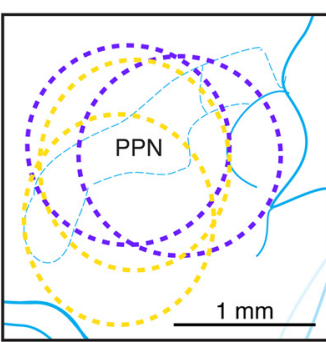

C
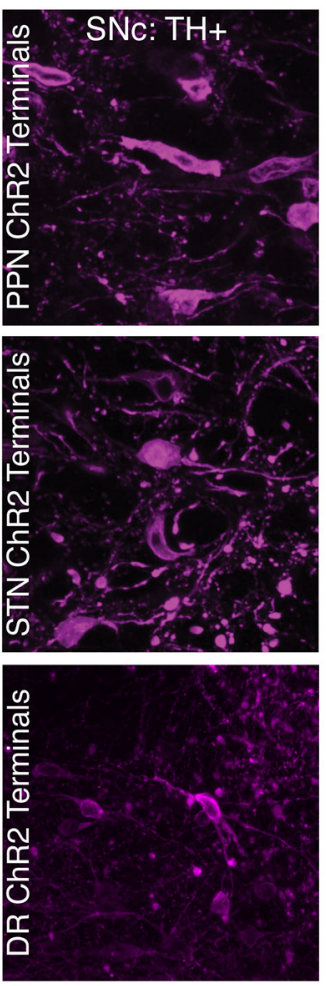
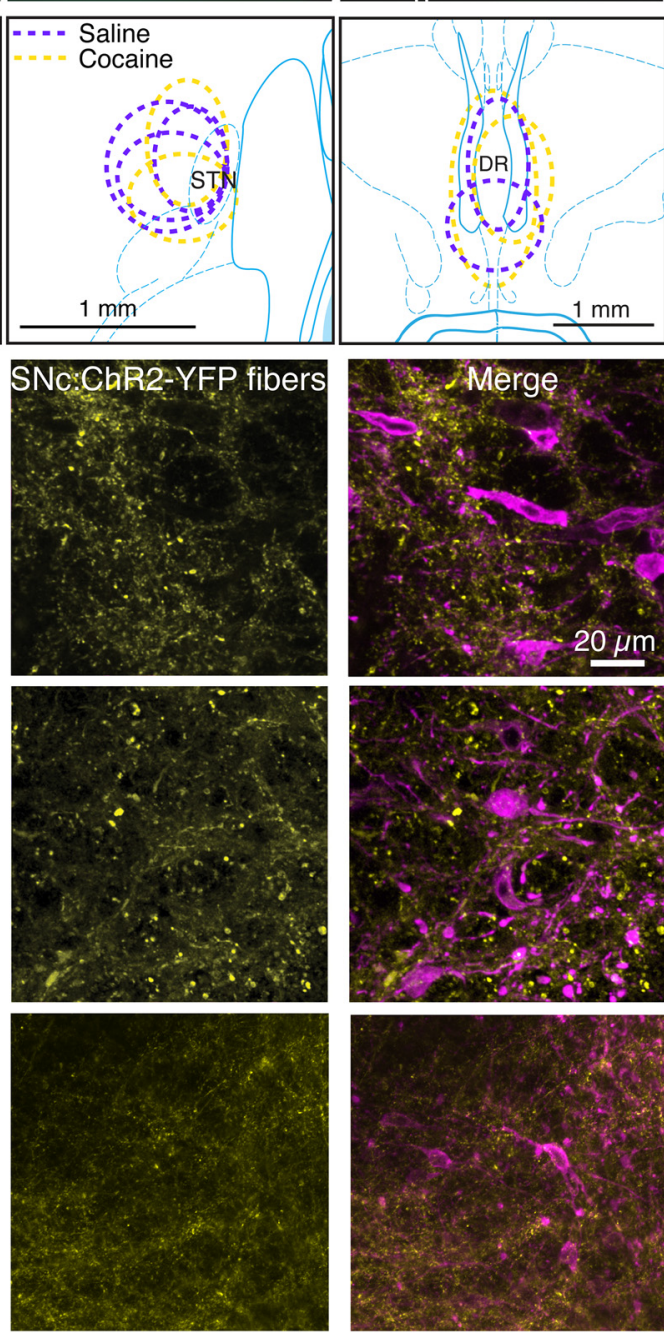

Figure 1. Injection of adeno-associated virus-encoded ChR2-YFP in the DR, PPN, and STN targets YFP expression to each nucleus and its projection targets. $\boldsymbol{A}$, Horizontal sections from mice injected with virus into PPN, STN, and DR, demonstrate YFP expression (green) throughout the nucleus 4 weeks after injection. DLL, Dorsal nucleus of the lateral meniscus; LPB, lateral parabrachial nucleus; LPBE, LPB external part; MiTg, microcellular tegmental nucleus; MPB, medial parabrachial nucleus; $m$ Rt, mesencephalic reticular formation; PaR, pararubral nucleus; PSTh, parasubthalamic nucleus; SNCD, substantia nigra, compact part, dorsal tier; SNR, substantia nigra, reticular part. $\boldsymbol{B}, 0$ vals represent the distribution of labeled neurons for mice used for control (magenta) and cocaine-injected (yellow) mice. C, YFP-labeled afferents (yellow) from PPN, STN, and DR are seen among anti-tyrosine hydroxylase-labeled dopamine neurons (magenta) in SNC.

\section{Results}

PPN afferents activate a different proportion of AMPA and NMDA receptors than STN or DR afferents

To selectively stimulate EPSCs from DR, PPN, or STN terminals, the light-sensitive opsin, channelrhodopsin (ChR2), was expressed in DR, PPN, or STN (Fig. $1 A, B$ ). Injections into DR, PPN, and STN resulted in dense axonal expression of ChR2-EYFP within SNc without infecting dopamine neurons (Fig. 1C). When the nucleus is correctly targeted with virus, a brief flash of light will stimulate EPSCs from that input (Fig. 2A,B, black traces). The intensity and duration of the laser are minimized to prevent desensitization of ChR2 and ensure responses are caused by propagating action potentials (see Fig. $6 C, D)$, and are then held constant for all optically evoked EPSCs for that neuron. The current stimulated by light is distinguished as an EPSC by two characteristics. First, there is a delay of $>1 \mathrm{~ms}$ between light onset to current onset, which is typical of electrically activated EPSCs. Second, a longer duration light pulse, 50-100 ms, does not produce an inward plateau current that decays when the light ends. Electrical stimulation was set to approximate optically evoked EPSCs in the same cell (Fig. 2A). Optically and electrically evoked EPSCs were then characterized for AMPA and NMDA receptor activation.

The AMPA-to-NMDA receptor-mediated current ratios were calculated by recording the stimulated EPSC (laser stimulation of DR, STN, or PPN terminals; or electrical stimulation of all afferents) at $+40 \mathrm{mV}$ before and after blocking NMDA receptors with 50-100 $\mu \mathrm{M}$ D-AP5 to reveal the AMPA receptormediated EPSC. Optical stimulation of PPN afferents (oPPN) evoked both AMPA and NMDA receptor-mediated currents in whole-cell recordings of $\mathrm{SNc}$ dopamine neurons (Fig. 2B, red and blue traces, respectively). The AMPA-to-NMDA ratio for oPPN-evoked EPSCs was significantly higher than the ratio measured from electrical stimulation of EPSCs (Fig. 2B, C; PPN, $0.82 \pm 0.11$, vs electrical, $0.46 \pm$ $0.07 ; n=15$ cells, 6 male mice, 1 female mouse; 8 cells, 3 male mice; one-way ANOVA, $F_{(3,36)}=5.656, p=0.0028$; Holm-

ture with goat anti-mouse Alexa 594 (1:1000) and goat anti-rabbit Alexa 488 (1:1000; Life Sciences) in PBS with 1\% normal goat serum and $0.1 \%$ Triton X-100. After $1-2 \mathrm{~h}$, slices were washed two times for $5 \mathrm{~min}$ in PBS with $0.05 \%$ Triton X-100, once for 10 min in PBS with 4',6-diamidino2-phenylindole dilactate (Life Technologies), and mounted in ProLongGold (Life Technologies). $Z$-stack images (12 images, with $1.0 \mu \mathrm{m}$ thick optical sections spaced by $0.5 \mu \mathrm{m}$ ) of the stained slices were collected on a Zeiss 510 meta using a $40 \times$ oil objective.
Sidak's adjusted $p=0.0471$ ). Optical stimulation of STN afferents (oSTN) predominantly activated NMDA receptor-mediated currents, similar to electrical stimulation (Fig. $2 B, C$; STN, $0.36 \pm$ 0.05 , vs electrical, $0.46 \pm 0.07 ; n=10$ cells, 2 male mice, 2 female mice; 8 cells, 3 male mice; Holm-Sidak's adjusted $p=0.8752$ ). Thus, oPPN-evoked EPSCs also had a significantly different AMPA-to-NMDA ratio from oSTN-evoked EPSCs (Fig. 2A; 


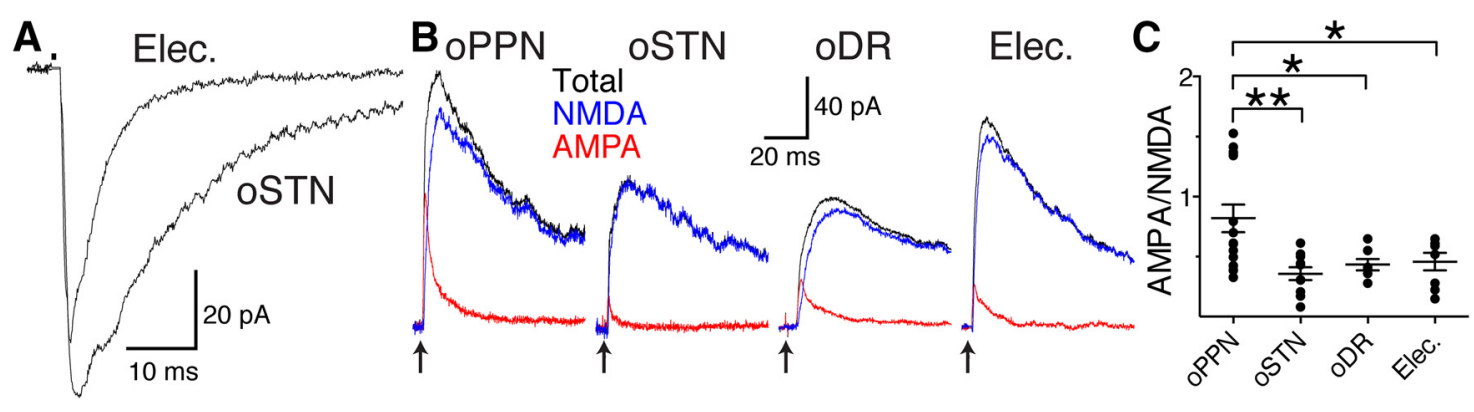

Figure 2. PPN, STN, and DR afferents have distinct postsynaptic receptor compositions in drug-naive mice. $A$, Example of a matched optogenetically evoked EPSC in STN with an electrically evoked EPSC in the same dopamine neuron. $\boldsymbol{B}$, Optogenetically evoked EPSCs (black traces; stimulation for all traces at arrows) from PPN (oPPN), STN (OSTN), DR (oDR), and electrically evoked EPSCs (Elec.; stimulus artifact removed) contain both NMDA (blue traces) and AMPA (red traces) receptor-mediated currents. C, AMPA-to-NMDA receptor-mediated current ratios. oPPN-evoked EPSCs had similar amount of AMPA receptor-mediated and NMDA receptor-mediated currents with a ratio near 1. oSTN-evoked, oDR-evoked, and electrically evoked EPSCs have AMPA-to-NMDA receptor-mediated current ratios of $<0.5 .{ }^{*} p<0.05,{ }^{* *} p<0.01$.

Holm-Sidak's adjusted $p=0.0047)$. Similar to STN and electrical stimulation, optical stimulation of DR afferents (oDR) predominantly activated NMDA receptor-mediated currents (Fig. $2 B, C$; DR, $0.44 \pm 0.05$, vs electrical, $0.46 \pm 0.07 ; n=7$ cells, 2 male mice, 1 female mouse; 8 cells, 3 male mice; Holm-Sidak's adjusted $p=0.8797$ ). Thus, oDR-evoked EPSCs also had a significantly different AMPA-to-NMDA ratio from oPPN-evoked EPSCs (Fig. 2 B, C; Holm-Sidak's adjusted $p=0.0471$ ).

To determine whether the AMPA receptor subunit composition differed at DR-innervated, STN-innervated, and PPN-innervated synapses, we pharmacologically isolated AMPA receptor-mediated currents and examined the current-voltage $(I-V)$ relationship. oDR-evoked and oPPN-evoked EPSCs at different holding potentials resulted in a linear $I-V$ relationship with a current near zero at a holding voltage of $0 \mathrm{mV}$ (Fig. 3A). However, oSTNevoked EPSCs had an $I-V$ relationship with inward rectification that preferentially fit a Woodhull model with an inward current at a holding voltage of $0 \mathrm{mV}$ (Fig. $3 A, B$; DR: $F_{(2,45)}=0.1672, p=$ $0.8466, r^{2}=0.70$ for linear fit, $n=8$ cells, 2 male mice; PPN: $F_{(2,51)}=0.9787, p=0.3828, r^{2}=0.53$ for linear fit, $n=9$ cells, 4 male mice; STN: $F_{(2,39)}=3.409, p=0.0432, r^{2}=0.43$ for Woodhull model; $n=7$ cells, 3 male mice, 2 female mice; Bowie and Mayer, 1995). This suggests that in naive animals, calciumpermeable AMPA receptors are preferentially localized to STNinnervated synapses. As calcium-permeable AMPA receptors are modulated by an internal polyamine block, we included $100 \mu \mathrm{M}$ spermine in the internal solution for several $I-V$ measurements for oPPN-evoked EPSCs and again found a linear $I-V$ relationship, not the Woodhull model, best fit the data regardless of internal (normal internal: $F_{(2,21)}=0.5623, p=0.5782, n=4$ cells, 3 male mice; internal + spermine: $F_{(2,27)}=0.6900, p=$ $0.5102, n=5$ cells, 1 male mouse). We also compared the inputs using a rectification index, the ratio of the current amplitude at a holding voltage of -60 to $+40 \mathrm{mV}$, to draw parallels with other studies of cocaine-mediated plasticity (Bellone and Lüscher, 2006; Argilli et al., 2008; Good and Lupica, 2010; Yuan et al., 2013). Consistent with the characterization of the full $I-V$ relationships, oSTN-evoked EPSCs had a significantly elevated rectification index compared with the very similar oPPN-evoked and oDR-evoked EPSCs (Fig. 3C; one-way ANOVA $F_{(2,35)}=13.57$, $p<0.0001$; STN vs PPN: $3.41 \pm 0.47$ vs $2.00 \pm 0.19$, HolmSidak's $p=0.0034, n=12$ cells each, 6 male mice, 2 female mice for STN; 6 male mice for PPN; STN vs DR: $3.41 \pm 0.47$ vs $1.36 \pm$ 0.09 , Holm-Sidak's $p<0.0001, n=12$ cells, 6 male mice, 2 female mice for STN; 14 cells, 3 male mice, 1 female mouse for DR; PPN vs DR: Holm-Sidak's $p=0.1161)$. This suggests that synapses innervated by STN preferentially activate calciumpermeable AMPA receptors.

To directly test for the presence of calcium-permeable AMPA receptors, we used a selective antagonist, either $100 \mu \mathrm{M}$ NASPM or $0.5 \mu \mathrm{M}$ JTx. There was no difference in effect between the antagonists (Fig. $3 D, E$; STN: $49.0 \pm 9 \%$ vs $34.4 \pm 9.6 \%$ inhibition by NASPM vs JTx; $n=3$ cells, 2 male mice, 1 female mouse for each; unpaired $t$ test $t_{(4)}=1.091, p=0.3365$ ) and so results from the antagonists were pooled. All inputs were sensitive to calcium-permeable AMPA receptor antagonists. However, oSTNevoked EPSCs were significantly more sensitive to calcium-permeable AMPA receptor antagonism relative to both oDR-evoked and oPPN-evoked EPSCs (Fig. 3D,E; STN: $41.7 \pm 6.8 \%$ of control onesample $t$ test $t_{(5)}=8.571, p=0.0004, n=6$ cells, 4 male mice, 2 female mice; PPN: $80.7 \pm 3.6 \%$ of control, one-sample $t$ test $t_{(7)}=$ 5.335, $p=0.0011, n=8$ cells, 3 male mice; DR: $72.4 \pm 6.2 \%$ of control, one-sample $t$ test $t_{(8)}=4.446, p=0.0022, n=9$ cells, 2 male mice; Fig. $3 D$; one-way ANOVA $F_{(2,20)}=11.45, p=0.0005$, STN vs PPN, Holm-Sidak's $p=0.0005$; STN vs DR, HolmSidak's $p=0.0027$; PPN vs DR, Holm-Sidak's $p=0.2880)$. Analysis of the time constant of decay for the AMPA receptor-mediated current did not confirm a significant difference between the inputs (Fig. $3 F$; PPN: $5.3 \pm 0.8 \mathrm{~ms}, n=13$ cells, 5 male mice, 1 female mouse; STN: $4.7 \pm 1.0 \mathrm{~ms}, n=12$ cells, 5 male mice, 2 female mice; DR: $7.9 \pm 1.2 \mathrm{~ms}, n=14$ cells, 3 male mice, 1 female mouse; one-way ANOVA, $\left.F_{(2,36)}=2.912, p=0.0673\right)$. Thus, oSTN-evoked EPSCs are typified by an abundance of NMDA receptors compared with AMPA receptors, and higher expression of calcium-permeable than of calcium-nonpermeable AMPA receptors. However, oPPN-evoked EPSCs are mediated by nearly equivalent amounts of NMDA and AMPA receptors, with most AMPA receptors being calcium impermeable and containing the GluA2 receptor subunit. Finally, oDR-evoked EPSCs are typified by an NMDA receptor function higher than that of AMPA receptors, similar to STN-innervated synapses, but lack calcium-permeable AMPA receptors, similar to PPN-innervated synapses.

\section{Cocaine increases NMDA receptor-mediated currents at PPN-innervated synapses while decreasing calcium-permeable AMPA receptor-mediated currents at STN-innervated synapses}

Following a single in vivo injection of cocaine $24 \mathrm{~h}$ before recording, electrically evoked EPSCs showed no significant difference in AMPA-to-NMDA ratio in SNc dopamine neurons when compared with control animals (Fig. $4 A, B$; control, $0.46 \pm 0.07$, vs 
A
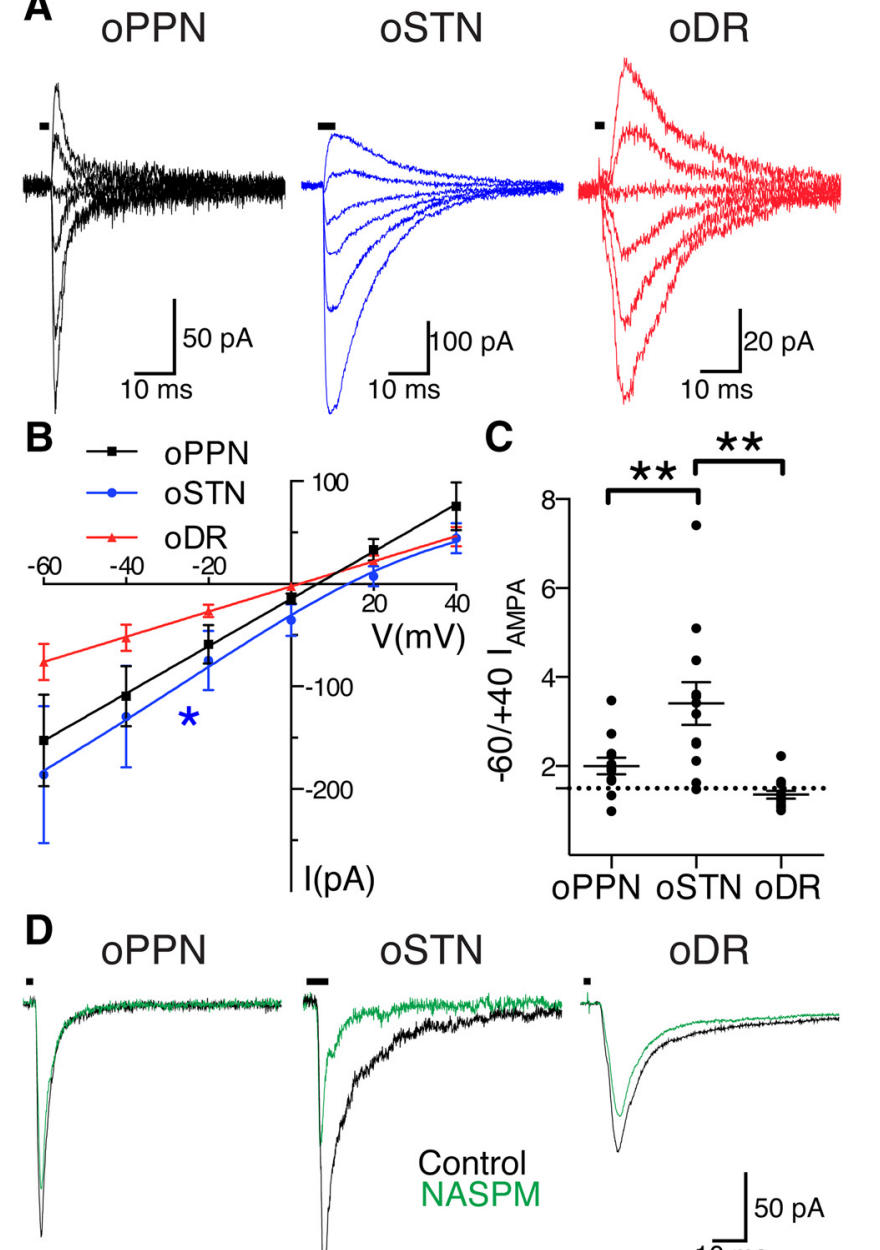

OSTN

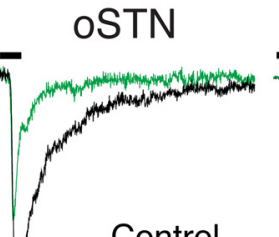

Control

NASPM

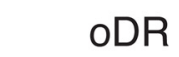

E
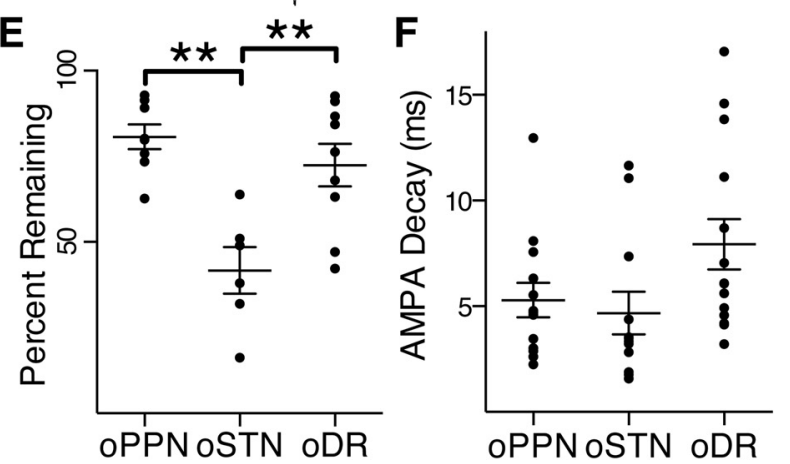

Figure 3. PPN, STN, and DR afferents activate different complements of AMPA receptors on dopamine neurons. $A$, oPPN-evoked (black), oSTN-evoked (blue), and oDR-evoked (red) AMPA receptor-mediated currents at holding voltages of $-60,-40,-20,0,+20$, and $+40 \mathrm{mV}$, from bottom trace to top trace. $B$, OPPN-evoked and oDR-evoked AMPA receptor-mediated currents (black and red) have a linear $I-V$ relationship, indicating that they contain the GluA2 subunit. OSTN-evoked AMPA receptor-mediated current with inwardly rectifying $I-V$ relationship (blue), not going through $0 \mathrm{pA}, 0 \mathrm{mV}$. C, Rectification index corresponding to the ratio of currents at a holding voltage of -60 to $+40 \mathrm{mV}$. The dashed line represents a ratio of 1.5, corresponding to a linear $I-V$ relationship. $\boldsymbol{D}$, oPPN evoked an inward current (black) that is marginally sensitive to NASPM (green). oSTN-evoked AMPA receptor-mediated current (black) is significantly inhibited by NASPM (green), indicating the presence of calcium-permeable AMPA receptors. oDR-evoked AMPA receptor-mediated current (black) is also partially inhibited by NASPM (green). $E$, Calcium-permeable AMPA receptor antagonists JTx and NASPM significantly decrease the normalized amplitude of AMPA receptor-mediated currents from OSTN compared with oPPN and oDR. $\boldsymbol{F}$, The time constant of decay for AMPA receptor-mediated currents produced at a holding voltage of $-60 \mathrm{mV} .{ }^{*} p<0.05,{ }^{* *} p<0.01$. cocaine-injected, $0.59 \pm 0.05, n=8$ cells, 3 male mice; 15 cells, 5 male mice; two-way ANOVA $F_{(3,76)}=4.081, p=0.0096$, HolmSidak's $p=0.6180$ ), similar to previous reports (Lammel et al., 2011). However, oPPN-evoked EPSCs had a significant decrease in AMPA-to-NMDA ratio (Fig. $4 A, B$; control, $0.82 \pm 0.11$, vs cocaine-injected, $0.46 \pm 0.07, n=15$ cells, 6 male mice, 1 female mouse; 10 cells, 2 male mice; Holm-Sidak's $p=0.0058$ ). In contrast to PPN, oSTN-evoked currents did not show any changes in AMPA-to-NMDA ratio following a single injection of cocaine (Fig. $4 A, B$; control, $0.36 \pm 0.05$, vs cocaine-injected, $0.47 \pm 0.08$, $n=10$ cells, 2 male mice, 2 female mice; 10 cells, 2 male mice, 2 female mice; Holm-Sidak's $p=0.6180$ ). Similar to STN, oDRevoked currents also did not show any changes in AMPA-to-NMDA ratio (Fig. $4 A, B$; control, $0.44 \pm 0.05$, vs cocaine-injected, $0.33 \pm$ $0.07, n=7$ cells, 2 male mice, 1 female mouse; 9 cells, 3 male mice; Holm-Sidak's $p=0.6180$ ).

To address whether the amount of AMPA or NMDA receptors changed at PPN-innervated synapses following a single exposure to cocaine, we examined the amplitude and kinetics of the AMPA and NMDA receptor-mediated currents. In all cases, the duration and power of laser stimulation was tuned to give a maximal response. We found no significant change in the AMPA receptormediated current for oPPN-evoked, oSTN-evoked, or oDR-evoked EPSCs (Fig. 4C; PPN: control, $73.7 \pm 15.0$ pA, vs cocaineinjected, $107.5 \pm 26.6 \mathrm{pA}, n=15$ cells, 6 male mice, 1 female mouse; 10 cells, 2 male mice; two-way ANOVA $F_{(2,55)}=1.093$, $p=0.3424$, Holm-Sidak's $p=0.2660 ;$ STN: control, $19.1 \pm 9.1$ $\mathrm{pA}$, vs cocaine-injected, $11.9 \pm 2.2 \mathrm{pA}, n=10$ cells, 2 male mice, 2 female mice; 10 cells, 2 male mice, 2 female mice; Holm-Sidak's $p=0.9337$; DR: control, $30.2 \pm 14.4 \mathrm{pA}$, vs cocaine-injected, $30.0 \pm 8.3 \mathrm{pA}, n=7$ cells, 2 male mice, 1 female mouse; 9 cells, 3 male mice; Holm-Sidak's $p=0.9912)$. However, there was a significant increase in the NMDA receptor-mediated current for oPPN-evoked EPSCs, but not for oSTN-evoked or oDR-evoked EPSCs, $1 \mathrm{~d}$ after a single injection of cocaine (Fig. $4 D$; PPN: control, $121.2 \pm 25.7 \mathrm{pA}$, vs cocaine-injected, $238.1 \pm 48.6 \mathrm{pA}, n=$ 15 cells, 6 male mice, 1 female mouse; 10 cells, 2 male mice; two-way ANOVA $F_{(2,54)}=3.343, p=0.0428$; Holm-Sidak's $p=$ 0.0049 ; STN: control, $49.0 \pm 17.0 \mathrm{pA}$, vs cocaine-injected, $30.8 \pm$ $6.5 \mathrm{pA}, n=10$ cells, 2 male mice, 2 female mice; 10 cells, 2 male mice, 2 female mice; Holm-Sidak's $p=0.6406$; DR: control, $41.2 \pm 10.7 \mathrm{pA}$, vs cocaine-injected, $91.6 \pm 15.7 \mathrm{pA}, n=6$ cells, 2 male mice, 1 female mouse; 9 cells, 3 male mice; Holm-Sidak's $p=0.4701$ ). The kinetics of the AMPA receptor-mediated EPSCs showed no significant changes in onset or decay kinetics of oPPN-evoked EPSCs (data not shown; rise time: control, $0.78 \pm$ $0.10 \mathrm{~ms}$, vs cocaine-injected, $0.72 \pm 0.09 \mathrm{~ms}, n=15$ cells, 6 male mice, 1 female mouse; 10 cells, 2 male mice; two-tailed $t$ test $p=$ 0.6532; $\tau$ decay: control, $6.1 \pm 0.6 \mathrm{~ms}$, vs cocaine-injected, $4.7 \pm$ $0.7 \mathrm{~ms}, n=19$ cells, 7 male mice, 2 female mice; 10 cells, 2 male mice; two-tailed $t$ test $p=0.1461)$. However, both onset and decay kinetics were hastened for oPPN-evoked NMDA receptormediated EPSCs (Fig. 4E; rise time: control. $3.22 \pm 0.16 \mathrm{~ms}$, vs cocaine-injected, $2.47 \pm 0.19 \mathrm{~ms}, n=15$ cells, 6 male mice, 1 female mouse; 10 cells, 2 male mice; two-tailed $t$ test $p=0.0073$; weighted $\tau$ decay: control, $129.6 \pm 15.2 \mathrm{~ms}$, vs cocaine-injected, $82.3 \pm 7.7 \mathrm{~ms}, n=15$ cells, 6 male mice, 1 female mouse; 10 cells, 2 male mice; two-tailed $t$ test $p=0.0116$ ). Thus, cocaine elicits changes in synapses on SNc dopamine neurons in an inputspecific manner, with a decrease in the AMPA-to-NMDA ratio at PPN-innervated synapses, but not at STN-innervated or DRinnervated synapses. Specifically, NMDA receptors appear to be 
A

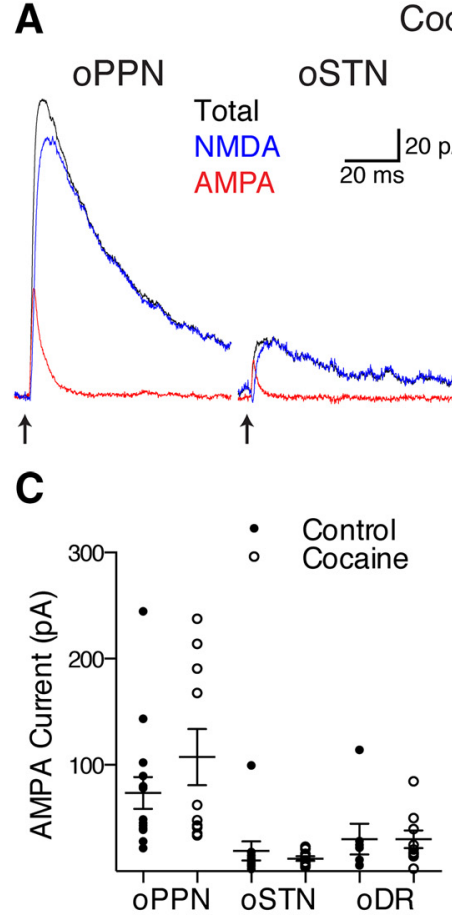

Cocaine oDR DR -

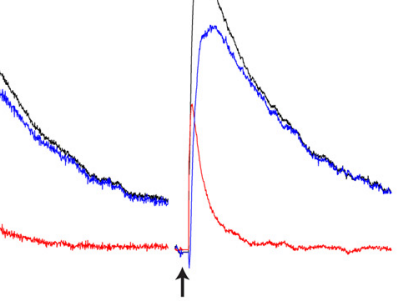

D

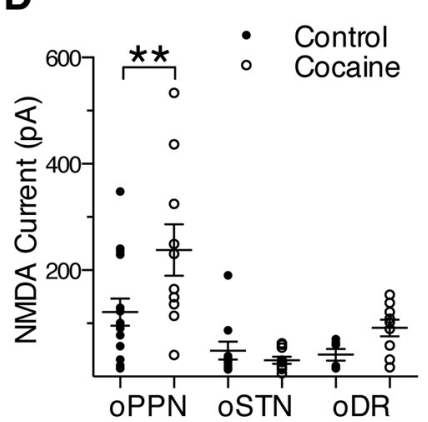

B

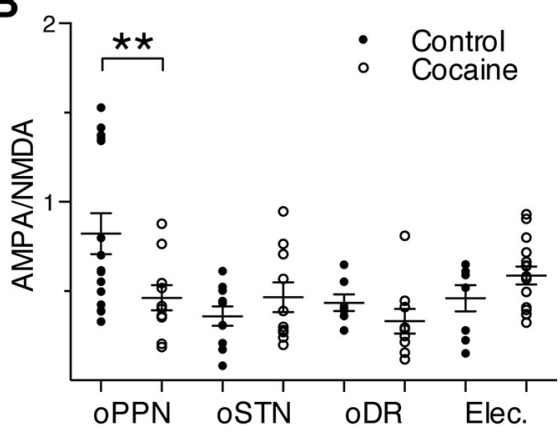

E

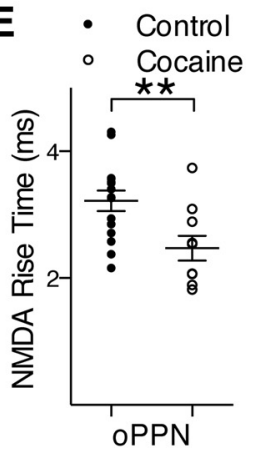

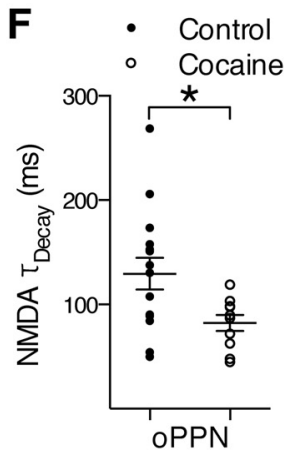

Figure 4. Exposure to cocaine decreases the proportion of AMPA receptors relative to NMDA receptors at PPN synapses by changing the NMDA receptor content. $\boldsymbol{A}$, After a single exposure to cocaine in vivo, oPPN-evoked AMPA (red) receptor-mediated and NMDA (blue) receptor-mediated currents become similar to oSTN-evoked, oDR-evoked, and electrically evoked (Elec.; stimulus artifact removed) currents. The oPPN-evoked EPSC and electrically evoked EPSC were recorded from the same dopamine neuron. Total EPSC is indicated by the traces in black. $\boldsymbol{B}$, Cocaine decreases the ratio of AMPA-to-NMDA currents at PPN inputs, but does not affect the AMPA-to-NMDA ratio of oSTN-evoked, oDR-evoked, or electrically evoked EPSCs. C, The amplitude of the AMPA receptor-mediated EPSCS evoked from oPPN, OSTN, and ODR, are not significantly affected after exposure to cocaine. $\boldsymbol{D}$, Exposure to cocaine significantly increases the amplitude of NMDA receptor-mediated currents evoked by oPPN, but not oSTN or oDR. $\boldsymbol{E}, \boldsymbol{F}$, NMDA receptor-mediated EPSCs evoked by oPPN show a reduced rise time $(\boldsymbol{E})$ and time constant of decay $(\boldsymbol{F})$ after cocaine administration. ${ }^{*} p<0.05,{ }^{* *} p<0.01$.

inserted, as those currents were augmented at the PPN-innervated synapses.

We tested whether exposure to cocaine also changes the AMPA receptor subtypes activated by the DR, STN, and PPN. Exposure to cocaine significantly decreased the rectification index of oSTN-evoked EPSCs, but did not affect oPPN-evoked or oDR-evoked EPSCs (Fig. 5A,B; STN: control, $3.4 \pm 0.5$, vs cocaine-injected, $2.4 \pm 0.2, n=12$ cells, 6 male mice, 2 female mice; 11 cells, 3 male micel female mouse, two-way ANOVA $F_{(2,66)}=3.331 p=0.0419$; Holm-Sidak's $p=0.0171$; PPN: control, $2.0 \pm 0.2$, vs cocaine-injected, $2.1 \pm 0.1, n=12$ cells, 6 male mice; 14 cells, 3 male mice, Holm-Sidak's $p=0.9414$; DR: control, $1.4 \pm 0.1$, vs cocaine-injected, $1.5 \pm 0.1, n=14$ cells, 3 male mice, 1 female mouse; 9 cells, 3 male mice; Holm-Sidak's $p=$ $0.9414)$. Given the change in rectification index, we tested for the sensitivity of the oSTN-evoked EPSC to calcium-permeable AMPA receptor antagonists. We found that the calcium-permeable AMPA receptor-mediated currents evoked by oSTN were significantly decreased by exposure to cocaine (STN: control, $42 \pm 7 \%$, vs cocaineinjected, $85 \pm 5 \%, n=6$ cells, 4 male mice, 2 female mice; 5 cells, 1 male mouse, 1 female mouse, two-way ANOVA $F_{(2,32)}=10.23$, $p=0.0004$, Holm-Sidak's $p<0.0001 ;$ PPN: control, $81 \pm 4 \%$, vs cocaine-injected, $78 \pm 5 \%, n=8$ cells, 3 male mice; 6 cells, 2 male mice, Holm-Sidak's $p=0.8998$; DR: control, $72 \pm 6 \%$, vs cocaine-injected, $69 \pm 4 \%, n=9$ cells, 2 male mice; 4 cells, 1 male mouse, Holm-Sidak's $p=0.8998)$. Thus, injection of cocaine in vivo decreased the proportion of calcium-permeable AMPA receptors specifically at STN-innervated synapses.

\section{Cocaine increases the probability of release at} STN-innervated and DR-innervated synapses

To determine whether exposure to cocaine causes presynaptic changes, we investigated the relative probability of release of STN, PPN, and DR afferents. To test the use of optical stimulation in measuring PPR of EPSCs, we verified that increasing light intensity and pulse duration caused a decrease in onset latency with an increase in amplitude (Fig. $6 C, D$ ). Increasing light intensity and pulse duration augments afferent fiber recruitment, thus increasing EPSC amplitude and decreasing onset latency. This suggests that stimulation with lower light intensity and shorter pulse duration evokes EPSCs by propagating action potentials (Tecuapetla et al., 2010). In the control condition, oSTN-evoked EPSCs exhibited paired-pulse facilitation (Fig. $6 A, B ; 1.21 \pm 0.09$; $n=7$ cells, 4 male mice, 1 female mouse), while oPPN-evoked, oDR-evoked, and electrically evoked EPSCs showed paired-pulse depression (Fig. $6 A, B$; PPN: $0.48 \pm 0.07, n=8$ cells, 4 male mice; DR: $0.82 \pm 0.11, n=11$ cells, 2 male mice 1 female mouse; electrical: $0.68 \pm 0.07, n=10$ cells, 6 male mice, 1 female mouse). Analysis with shorter and longer interstimulus intervals showed paired-pulse depression leading to paired-pulse facilitation for STN-innervated synapses, while PPN and DR afferents continually showed paired-pulse depression (data not shown). In vivo exposure to cocaine did not significantly change the probability of release for electrically evoked or oPPN-evoked EPSCs (Fig. $6 A, B$; electrical: control, $0.68 \pm 0.07$, vs cocaine-injected. $0.85 \pm$ $0.06, n=10$ cells, 6 male mice, 1 female mouse; 18 cells, 5 male mice, two-way ANOVA $F_{(3,79)}=9.447, p<0.0001$, Holm-Sidak's $p=0.1799$; PPN: control, $0.48 \pm 0.07$, vs cocaine-injected, 

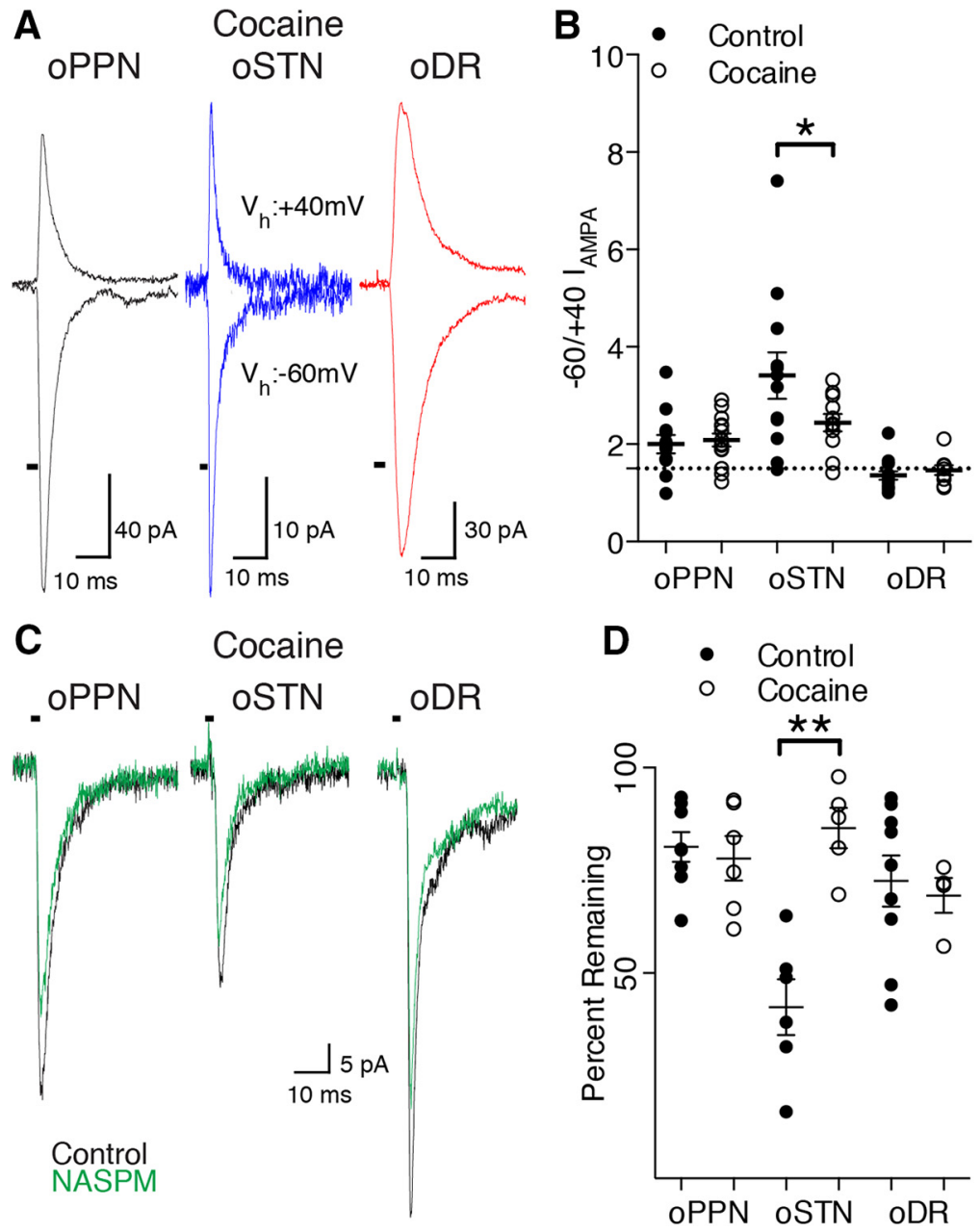

Figure 5. A single injection of cocaine in vivo causes removal of calcium-permeable AMPA receptors at STN synapses. $A$, After exposure to cocaine, OPPN-evoked (black), OSTN-evoked (blue), and oDR-evoked (red) EPSCs have similar rectification of AMPA receptor-mediated currents. $\boldsymbol{B}$, Rectification index of AMPA receptor-mediated currents from individual afferents in control (saline and naive) and cocaine-treated animals. The dashed line represents a ratio of 1.5 , corresponding to a linear $I-V$ relationship. C, After exposure to cocaine, oPPN-evoked and oDR-evoked inward currents (black) are partially sensitive to NASPM (green). After cocaine injection, 0STN-evoked AMPA receptor-mediated current (black) is only partially sensitive to NASPM (green), indicating the relative decrease of calcium-permeable AMPA receptors when compared with the same input in control animals. D, Calciumpermeable AMPA receptor antagonists JTx and NASPM do not significantly decrease the normalized amplitude of AMPA receptormediated currents from the oSTN, oDR, or oPPN after cocaine exposure in vivo. ${ }^{*} p<0.05,{ }^{* *} p<0.01$.

$0.42 \pm 0.06 ; n=8$ cells, 4 male mice; 11 cells, 2 male mice, Holm-Sidak's $p=0.5950)$. However, oSTN-evoked EPSCs showed a switch from paired-pulse facilitation to depression following cocaine exposure (Fig. $6 A, B$; control, $1.21 \pm 0.09$, vs cocaine-injected, $0.61 \pm 0.05, n=7$ cells, 4 male mice, 1 female mouse; 11 cells, 2 male mice, 1 female mouse, Holm-Sidak's $p<$ 0.0001). The PPR of oDR-evoked EPSCs was also significantly decreased by exposure to cocaine (Fig. $6 A, B$, control, $0.82 \pm$ 0.11 , vs cocaine-injected, $0.48 \pm 0.08, n=11$ cells, 2 male mice, 1 female mouse; 11 cells, 3 male mice, Holm-Sidak's $p=0.0049)$.

\section{Discussion}

Synaptic properties are afferent-specific

Midbrain dopamine neurons receive excitatory inputs from discrete brain nuclei, which could underlie heterogeneous neuronal responses (Geisler et al., 2007; Watabe-Uchida et al., 2012; Tian et al., 2016). Previous studies using thick or oblique sections to preserve axon tracts to SNc showed that minimal, focal electrical stimulation of STN neurons evoked postsynaptic potentials me- diated by AMPA and NMDA receptors, similar to PPN-evoked potentials (Futami et al., 1995; Iribe et al., 1999; Kang and Futami, 1999). Using an optogenetic strategy to selectively stimulate identified inputs, we compared the synaptic properties of DR, STN, and PPN afferents to SNc dopamine neurons. oPPN-mediated EPSCs elicited an AMPA-to-NMDA ratio suggesting equivalent expression of each receptor type. In contrast, oSTN-activated and oDR-activated EPSCs were similar to electrical activation with significantly more of the EPSC being NMDA receptormediated. This suggests that submaximal electrical stimulation preferentially activates STN and DR afferents. However, this might be due to the spatial orientation of the stimulating electrode, the afferents innervating the dopamine cell, and efficiency of viral transduction in the target nuclei. oDR-evoked, oSTN-evoked, and oPPN-evoked EPSCs were further characterized by the AMPA receptor subtype. oDR-activated and oPPN-activated AMPA receptor-mediated EPSCs exhibited a linear $I-V$ relationship and were relatively insensitive to a calcium-permeable AMPA receptor antagonist (Isaac et al., 2007). By contrast, oSTN-evoked EPSCs were mediated by AMPA receptors with an inwardly rectifying $I-V$ relationship and sensitivity to calcium-permeable AMPA receptor antagonists, suggesting the lack of GluA2 subunits. Thus, at baseline, dopamine neurons adjust the weight of individual inputs by manipulating both the NMDA and AMPA receptor content.

\section{Cocaine-induced plasticity is afferent-selective}

Previous research on cocaine-evoked changes on dopamine neurons in the VTA suggests that an increase in AMPA-to-

NMDA ratio occurs through insertion of calcium-permeable AMPA receptors at electrically activated synapses (Bellone and Lüscher, 2006). Exposure to cocaine has been shown to also change the NMDA receptor subunits expressed on VTA dopamine neurons (Schilström et al., 2006; Mameli et al., 2011; Yuan et al., 2013). While these studies were done using electrical stimulation, focal stimulation of PPN showed a similar insertion of calcium-permeable AMPA receptors after cocaine injection, so it was still unclear whether cocaine affects all synapses or synapses from specific afferents (Good and Lupica, 2010).

Exposure to cocaine caused changes to oSTN-evoked EPSCs, altering presynaptic release properties and removing inward rectifying, calcium-permeable AMPA receptors. oDR-evoked EPSCs showed that cocaine augmented presynaptic release properties without affecting postsynaptic receptors. oPPN-evoked EPSCs had a reduction in the AMPA-to-NMDA ratio, and unchanged presynaptic efficacy. Consistent with previous reports, we found no cocaine-induced changes in AMPA-to-NMDA ratio or PPR of 
electrically stimulated EPSCs to SNc dopamine neurons (Lammel et al., 2011).

While the AMPA-to-NMDA ratio decreased for PPN-innervated synapses, cocaine caused a qualitatively different change to STN-innervated synapses by exchanging the type of AMPA receptors functioning at STN-innervated synapses without changing the AMPA-to-NMDA ratio. Our evidence suggests that cocaine administration specifically redistributes the NMDA receptor content at the PPN synapse, as the amplitude of the NMDA receptor-mediated EPSC changed along with the kinetics. The metric of AMPAto-NMDA ratio as a gauge for synaptic strength, which assumes that NMDA receptor content does not change, may not be as generally applicable as previously thought. In our study, either NMDA receptors are potentiated or AMPA receptors are depressed, based upon the input. Previous research has suggested that signaling from NMDA receptors and D1-type dopamine receptors underlie changes in AMPA-to-NMDA ratio changes at synapses on VTA dopamine neurons (Ungless et al., 2001; Dong et al., 2004). However, as those studies showed an increase in AMPA-toNMDA ratio with an insertion of calciumpermeable AMPA receptors, the signaling mechanisms may be distinct between VTA and SNc dopamine cells. More recent evidence has shown a change in NMDA receptor function, due to the increase in expression of NR3a-containing NMDA receptors (Yuan et al., 2013; Creed et al., 2016). However, this causes an increase in the time constant of decay, suggesting the synaptic changes at synapses on VTA dopamine neurons are distinct from the changes seen at PPNinnervated synapses on SNc dopamine neurons. Given that the changes of STN-innervated and PPN-innervated synapses are qualitatively different and neither effect is predicted by electrical stimulation of glutamate afferents, our data demonstrate that cocaine causes selective effects to specific inputs to dopamine neurons.

STN-innervated synapses had a loss of calcium-permeable AMPA receptors and a reduction in PPRs, thus both a presynaptic and postsynaptic effect of cocaine occurs at this synapse. Activation of $\mathrm{mGlu}_{1}$ receptors may be required for the loss of the calcium-permeable AMPA receptors postsynaptically, whereas presynaptic $\mathrm{mGlu}_{1}$ receptor activation causes long-term depression (Lüscher and Huber, 2010). However, postsynaptic activation of $\mathrm{mGlu}_{1}$ receptors can also cause presynaptic potentiation (Lapointe et al., 2004). Thus, activation of $\mathrm{mGlu}_{1}$ receptors could cause a coordinated loss of a type of AMPA receptor postsynaptically while strengthening the release probability presynaptically.

DR-innervated synapses were relatively insensitive to cocaine postsynaptically, showing that dopamine neurons can differentially modulate their receptors based upon the input. However, cocaine did cause a decrease in the PPR, similar to the decrease in
PPR at STN-innervated synapses. This presynaptic effect of cocaine proves to be specific, as neither electrically innervated nor PPN-innervated synapses showed any change in PPR. This shows that the effects of cocaine do not necessarily affect both sides of the synapse simultaneously.

By stimulating specific glutamate inputs to $\mathrm{SNc}$ dopamine neurons, we have demonstrated that cocaine differentially modulates excitatory inputs to SNc dopamine neurons. While often thought to be involved in psychomotor behaviors, SNc dopamine neurons are also involved in associations of natural rewards or cocaine with cues (Hassani et al., 2001; Ito et al., 2002; Rossi et al., 2013). The PPN, STN, and DR are thought to convey specific aspects of reward-cue conditioning to SNc dopamine neurons. Similar to stimulation of the SNc or VTA, stimulation of the DR can act as its own reward, supporting instrumental learning and inducing condition place preference (Liu et al., 2014; McDevitt et al., 2014; Qi et al., 2014). PPN neuronal activity is sensitive to sensory-based changes in reward context (Norton et al., 2011). Neurons within the STN respond to different types of reward, such as natural or drug rewards (Baunez et al., 2005). While lesion experiments have suggested that the PPN and STN may encode motivation for learning drug-cue associations, STN does this at the expense of natural reward-cue associations (Bechara 
and van der Kooy, 1989; Baunez et al., 2005). The present results show how cocaine can alter the influence each input has on dopamine neuron activity at the cellular level. Instead of having the same response to every glutamate input, dopamine neurons modulate receptor expression at specific synapses, tuning their responses to each input. Cocaine would then co-opt this ability by preferentially enhancing synaptic responses that increase the influence of contextual environmental stimuli linked to cocaine administration.

\section{References}

Argilli E, Sibley DR, Malenka RC, England PM, Bonci A (2008) Mechanism and time course of cocaine-induced long-term potentiation in the ventral tegmental area. J Neurosci 28:9092-9100. CrossRef Medline

Baunez C, Dias C, Cador M, Amalric M (2005) The subthalamic nucleus exerts opposite control on cocaine and 'natural' rewards. Nat Neurosci 8:484-489. CrossRef Medline

Bechara A, van der Kooy D (1989) The tegmental pedunculopontine nucleus: a brain-stem output of the limbic system critical for the conditioned place preferences produced by morphine and amphetamine. J Neurosci 9:3400-3409. Medline

Bellone C, Lüscher C (2006) Cocaine triggered AMPA receptor redistribution is reversed in vivo by mGluR-dependent long-term depression. Nat Neurosci 9:636-641. CrossRef Medline

Bowie D, Mayer ML (1995) Inward rectification of both AMPA and kainate subtype glutamate receptors generated by polyamine-mediated ion channel block. Neuron 15:453-462. CrossRef Medline

Creed M, Kaufling J, Fois GR, Jalabert M, Yuan T, Lüscher C, Georges F, Bellone C (2016) Cocaine exposure enhances the activity of ventral tegmental area dopamine neurons via calcium-impermeable NMDARs. J Neurosci 36:10759-10768. CrossRef Medline

Dong Y, Saal D, Thomas M, Faust R, Bonci A, Robinson T, Malenka RC (2004) Cocaine-induced potentiation of synaptic strength in dopamine neurons: behavioral correlates in GluRA(-/-) mice. Proc Natl Acad Sci U S A 101:14282-14287. CrossRef Medline

Futami T, Takakusaki K, Kitai ST (1995) Glutamatergic and cholinergic inputs from the pedunculopontine tegmental nucleus to dopamine neurons in the substantia nigra pars compacta. Neurosci Res 21:331-342. CrossRef Medline

Geisler S, Derst C, Veh RW, Zahm DS (2007) Glutamatergic afferents of the ventral tegmental area in the rat. J Neurosci 27:5730-5743. CrossRef Medline

Goertz RB, Wanat MJ, Gomez JA, Brown ZJ, Phillips PE, Paladini CA (2015) Cocaine increases dopaminergic neuron and motor activity via midbrain $\alpha 1$ adrenergic signaling. Neuropsychopharmacology 40:1151-1162. CrossRef Medline

Good CH, Lupica CR (2010) Afferent-specific AMPA receptor subunit composition and regulation of synaptic plasticity in midbrain dopamine neurons by abused drugs. J Neurosci 30:7900-7909. CrossRef Medline

Hassani OK, Cromwell HC, Schultz W (2001) Influence of expectation of different rewards on behavior-related neuronal activity in the striatum. J Neurophysiol 85:2477-2489. Medline

Heikkinen AE, Möykkynen TP, Korpi ER (2009) Long-lasting modulation of glutamatergic transmission in VTA dopamine neurons after a single dose of benzodiazepine agonists. Neuropsychopharmacology 34:290-298. CrossRef Medline

Ilango A, Kesner AJ, Keller KL, Stuber GD, Bonci A, Ikemoto S (2014) Similar roles of substantia nigra and ventral tegmental dopamine neurons in reward and aversion. J Neurosci 34:817-822. CrossRef Medline

Iribe Y, Moore K, Pang KC, Tepper JM (1999) Subthalamic stimulationinduced synaptic responses in substantia nigra pars compacta dopaminergic neurons in vitro. J Neurophysiol 82:925-933. Medline

Isaac JT, Ashby MC, McBain CJ (2007) The role of the GluR2 subunit in AMPA receptor function and synaptic plasticity. Neuron 54:859-871. CrossRef Medline

Ito R, Dalley JW, Howes SR, Robbins TW, Everitt BJ (2000) Dissociation in conditioned dopamine release in the nucleus accumbens core and shell in response to cocaine cues and during cocaine-seeking behavior in rats. J Neurosci 20:7489-7495. Medline
Ito R, Dalley JW, Robbins TW, Everitt BJ (2002) Dopamine release in the dorsal striatum during cocaine-seeking behavior under the control of a drug-associated cue. J Neurosci 22:6247-6253. Medline

Kang Y, Futami T (1999) Arrhythmic firing in dopamine neurons of rat substantia nigra evoked by activation of subthalamic neurons. J Neurophysiol 82:1632-1637. Medline

Lammel S, Ion DI, Roeper J, Malenka RC (2011) Projection-specific modulation of dopamine neuron synapses by aversive and rewarding stimuli. Neuron 70:855-862. CrossRef Medline

Lapointe V, Morin F, Ratté S, Croce A, Conquet F, Lacaille JC (2004) Synapse-specific mGluR1-dependent long-term potentiation in interneurones regulates mouse hippocampal inhibition. J Physiol 555:125-135. CrossRef Medline

Liu Z, Zhou J, Li Y, Hu F, Lu Y, Ma M, Feng Q, Zhang JE, Wang D, Zeng J, Bao J, Kim JY, Chen ZF, El Mestikawy S, Luo M (2014) Dorsal raphe neurons signal reward through 5-HT and glutamate. Neuron 81:1360-1374. CrossRef Medline

Lüscher C, Huber KM (2010) Group 1 mGluR-dependent synaptic longterm depression: mechanisms and implications for circuitry and disease. Neuron 65:445-459. CrossRef Medline

Mameli M, Bellone C, Brown MT, Lüscher C (2011) Cocaine inverts rules for synaptic plasticity of glutamate transmission in the ventral tegmental area. Nat Neurosci 14:414-416. CrossRef Medline

McDevitt RA, Tiran-Cappello A, Shen H, Balderas I, Britt JP, Marino RAM, Chung SL, Richie CT, Harvey BK, Bonci A (2014) Serotonergic versus nonserotonergic dorsal raphe projection neurons: differential participation in reward circuitry. Cell Rep 8:1857-1869. CrossRef Medline

Norton AB, Jo YS, Clark EW, Taylor CA, Mizumori SJ (2011) Independent neural coding of reward and movement by pedunculopontine tegmental nucleus neurons in freely navigating rats. Eur J Neurosci 33:1885-1896. CrossRef Medline

Qi J, Zhang S, Wang HL, Wang H, de Jesus Aceves Buendia J, Hoffman AF, Lupica CR, Seal RP, Morales M (2014) A glutamatergic reward input from the dorsal raphe to ventral tegmental area dopamine neurons. Nat Commun 5:5390. CrossRef Medline

Rossi MA, Sukharnikova T, Hayrapetyan VY, Yang L, Yin HH (2013) Operant self-stimulation of dopamine neurons in the substantia nigra. PLoS One 8:e65799. CrossRef Medline

Saal D, Dong Y, Bonci A, Malenka RC (2003) Drugs of abuse and stress trigger a common synaptic adaptation in dopamine neurons. Neuron 37: 577-582. CrossRef Medline

Schilström B, Yaka R, Argilli E, Suvarna N, Schumann J, Chen BT, Carman M, Singh V, Mailliard WS, Ron D, Bonci A (2006) Cocaine enhances NMDA receptor-mediated currents in ventral tegmental area cells via dopamine D5 receptor-dependent redistribution of NMDA receptors. J Neurosci 26:8549-8558. CrossRef Medline

Tecuapetla F, Patel JC, Xenias H, English D, Tadros I, Shah F, Berlin J, Deisseroth K, Rice ME, Tepper JM, Koos T (2010) Glutamatergic signaling by mesolimbic dopamine neurons in the nucleus accumbens. J Neurosci 30:7105-7110. CrossRef Medline

Tian J, Huang R, Cohen JY, Osakada F, Kobak D, Machens CK, Callaway EM, Uchida N, Watabe-Uchida M (2016) Distributed and mixed information in monosynaptic inputs to dopamine neurons. Neuron 91:1374-1389. CrossRef Medline

Ungless MA, Whistler JL, Malenka RC, Bonci A (2001) Single cocaine exposure in vivo induces long-term potentiation in dopamine neurons. Nature 411:583-587. CrossRef Medline

Watabe-Uchida M, Zhu L, Ogawa SK, Vamanrao A, Uchida N (2012) Whole-brain mapping of direct inputs to midbrain dopamine neurons. Neuron 74:858-873. CrossRef Medline

Wolf ME (1998) The role of excitatory amino acids in behavioral sensitization to psychomotor stimulants. Prog Neurobiol 54:679-720. CrossRef Medline

Yuan T, Mameli M, O'Connor EC, O' Connor EC, Dey PN, Verpelli C, Sala C, Perez-Otano I, Lüscher C, Bellone C (2013) Expression of cocaine-evoked synaptic plasticity by GluN3A-containing NMDA receptors. Neuron 80: 1025-1038. CrossRef Medline

Zahniser NR, Peris J, Dwoskin LP, Curella P, Yasuda RP, O'Keefe L, Boyson SJ (1988) Sensitization to cocaine in the nigrostriatal dopamine system. NIDA Res Monogr 88:55-77. Medline 